\title{
Design and Analysis of a Cam-Actuated Wearable-Chair
}

\author{
Adinda Hadirah Mohd Zin, Shamsul Anuar Shamsudin, Mohd Nizam Sudin, Mohd Nazim Abdul \\ Rahman, Zairulazha Zainal
}

\begin{abstract}
This work analyzes the feasibility of a design of a foldable chair that is strapped onto the user. It can be used anywhere as the user needs to sit. Many chairless chairs or wearable-chairs have been invented over the years. Here, the focus is on the findings from the simulations and analyses performed to investigate the critical stress area in the design assembly as well as its factor of safety. The simulations included in this paper are motion analysis and stress analysis. The outcome of this investigation is that this design is be able to deliver its purpose if it were to be manufactured for safe use by the masses.
\end{abstract}

Keywords : Cam-actuated, wearable-chair, development, analysis

\section{INTRODUCTION}

A wearable-chair or chairless chair is one of the useful inventions in recent design history. However, there are not many wearable-chair designs available in current market. The companies involved in the invention and development of such a device are mostly from Switzerland, Japan and Korea.

The world's first chair-less chair was designed by a Swiss design studio, Sapetti and then developed by Noonee in Zurich in 2014. The motivation is to enable the user to sit anywhere at any time without using the hand to carry the chair around [1]. Fig. 1 shows the initial concept considered in this work. Here, the angle between standing and sitting positions is suggested to be $18^{\circ}$.

Stinson [2] reported about the lighter Noonee design and compared it to the tool-holding Fortis developed by Lockheed Martin. The latter is a device that is basically a heavier exoskeleton. However, it can also be carried anywhere and designed for factory workers to be able to walk normally and can sit wherever they have to. The design is

Revised Manuscript Received on February 05, 2020.

* Correspondence Author

Adinda Hadirah Mohd Zin, Faculty of Mechanical Engineering, Universiti Teknikal Malaysia Melaka, 75450 Ayer Keroh, Melaka, Malaysia. Email: adindahadirah@gmail.com

Shamsul Anuar Shamsudin, Centre for Advanced Research on Energy (CARe), Universiti Teknikal Malaysia Melaka, 75450 Ayer Keroh, Melaka, Malaysia. Email: shamanuar@utem.edu.my

Mohd Nizam Sudin*, Centre for Advanced Research on Energy (CARe), Universiti Teknikal Malaysia Melaka, Technology Campus, 75450 Ayer Keroh, Melaka, Malaysia. Email: nizamsudin@utem.edu.my

Mohd Nazim Abdul Rahman, Centre for Advanced Research on Energy (CARe), Universiti Teknikal Malaysia Melaka, 75450 Ayer Keroh, Melaka, Malaysia. Email: nazim@utem.edu.my

Zairulazha Zainal, Centre for Robotics and Industrial Automation (CeRIA), Universiti Teknikal Malaysia Melaka, 76100 Durian Tunggal Melaka, Malaysia. Email: zairulazha@utem.edu.my

(C) The Authors. Published by Blue Eyes Intelligence Engineering and Sciences Publication (BEIESP). This is an open access article under the CC BY-NC-ND license (http://creativecommons.org/licenses/by-nc-nd/4.0/) also adjustable to suit with the user's height [3]. It has a push button to lock the frame at the desired angle, preventing the device from touching the ground unless in a static position. The device is also equipped with belts and wraps to secure the device onto the user's legs [1]. Nevertheless, it is not an easy task to design for ergonomics and to let the users move freely when using the chairless chair.

In the end, this innovation contributes in minimizing the negative impact on the industry workers' health and optimize the area in workplace by eliminating the use of conventional chairs.
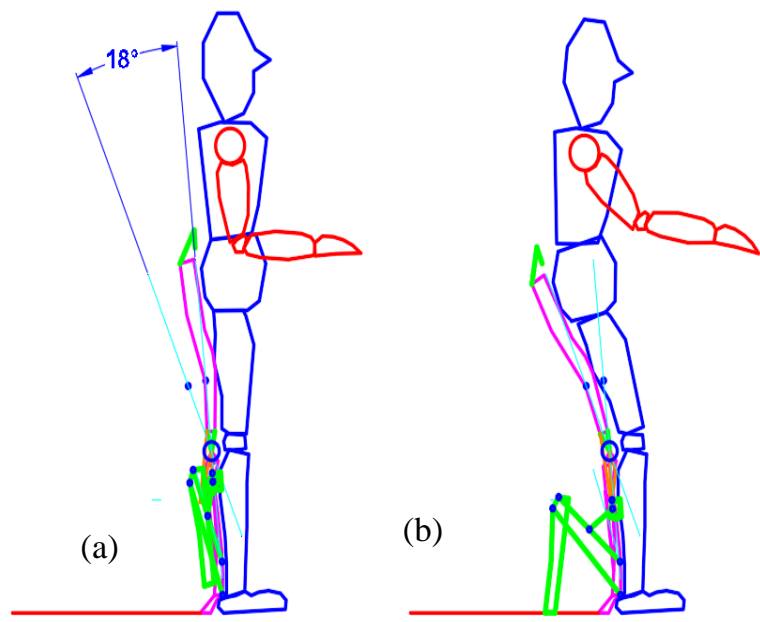

Fig. 1.Initial design of the new chairless chair. (a) The chair is folded when the user is standing. (b) The chair is deployed when the user is resting.

\section{DESIGN ASSEMBLY}

At first, to achieve the final design, the mechanical engineering design methods were performed, which included survey analysis, functional decomposition, quality functional development, product design specification and concept generation. From the survey, the customer or prospective user requirements could be identified. This is then listed in the House of Quality in Fig. 2 that helps in determining product specifications. Many other criteria were also considered such as specific user needs, manufacturing methods, service life and market segments.

This work considered many subfunctions for the device. There are many options for each subfunctions and these can create many design concepts for this product. Table I shows the morphological chart and the possible solutions they offer. Such an approach is discussed by Pahl, Beitz, Feldhusen and Grote in [4]. 


\section{Design and Analysis of a Cam-Actuated Wearable-Chair}

Fig. 3 shows many conceptual designs can be generated from the combinations of the morphological chart, A conceptual design is using product design weighted scoring selection method shown in Ulrich and Eppinger [5], where one concept was chosen to be developed further. SolidWorks 2014 computer aided design (CAD) software was used to draw and assemble the solid model of Wearable-chair. The sub parts in the design assembly included the cover parts, core parts, seat, cam follower, fasteners and connectors.

The winning concept utilizes a cam to transfer motion from the upper part of the mechanism to the lower that deploys the stand at the back of the device. Details on procedure for cam design can be found in literature like Myszka [6].

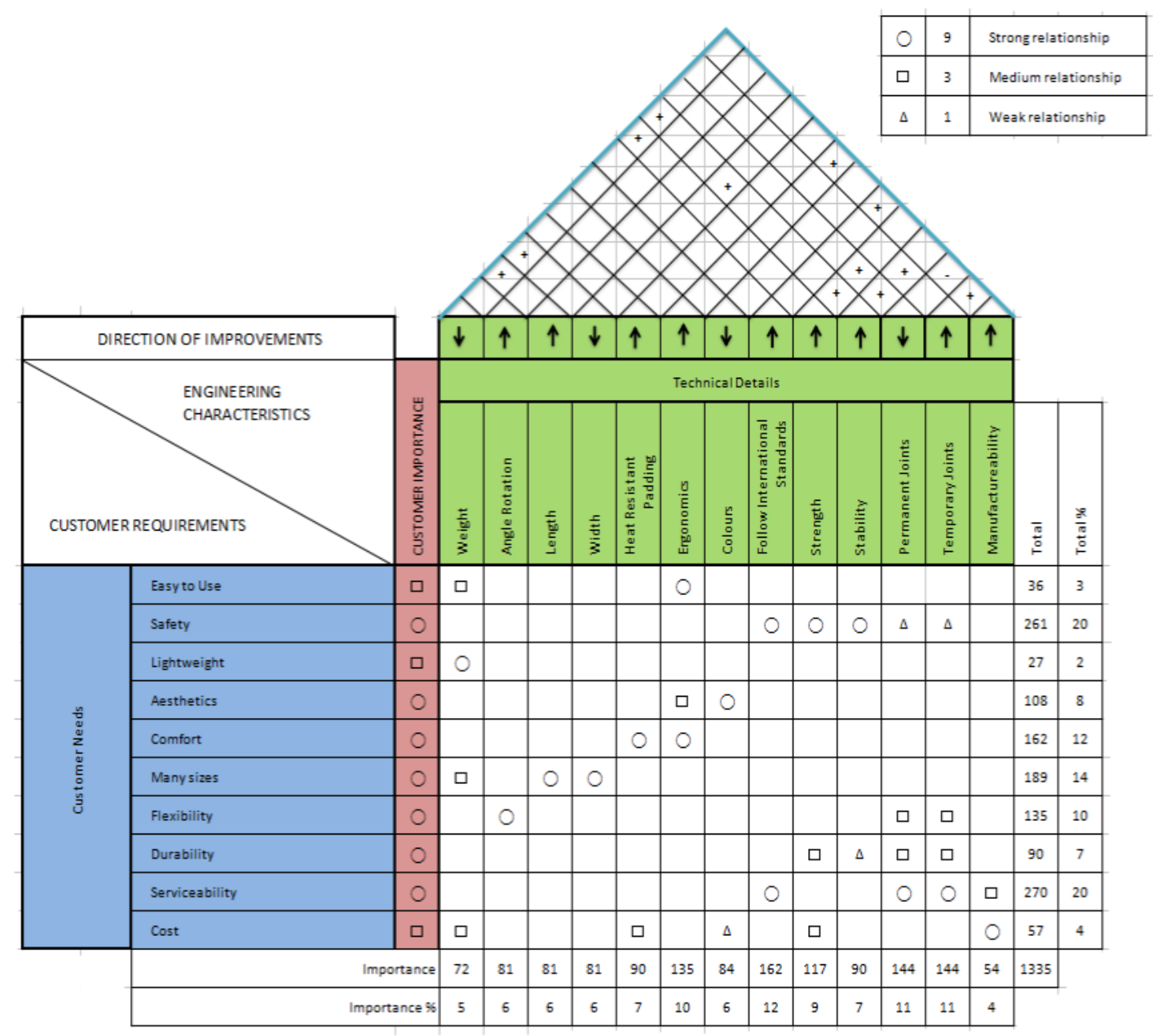

Fig. 2.Project House of Quality.
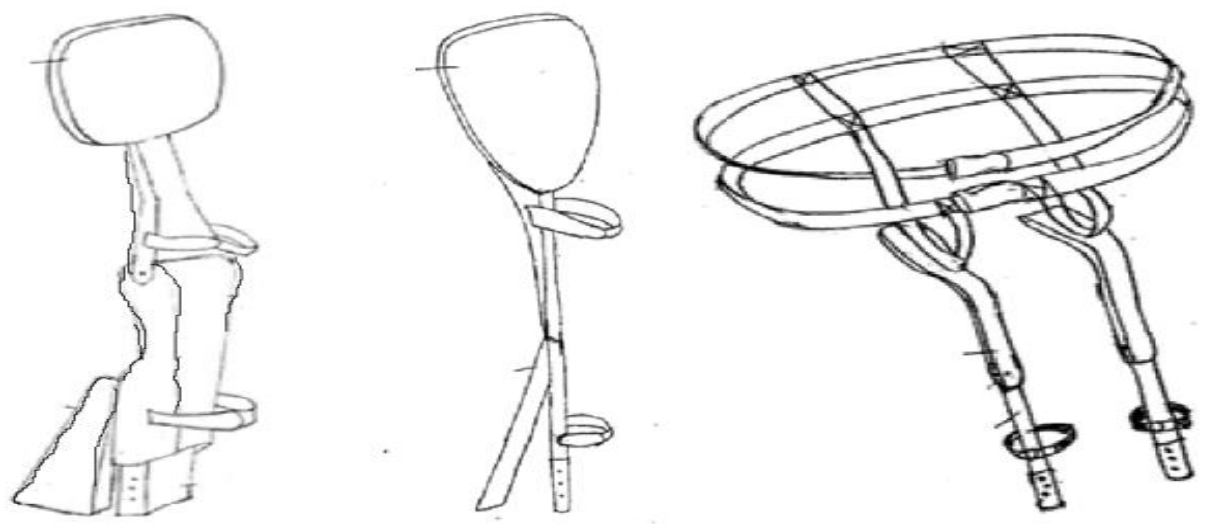

Fig. 3.Three conceptual designs generated. 
Table- II: The morphological chart.

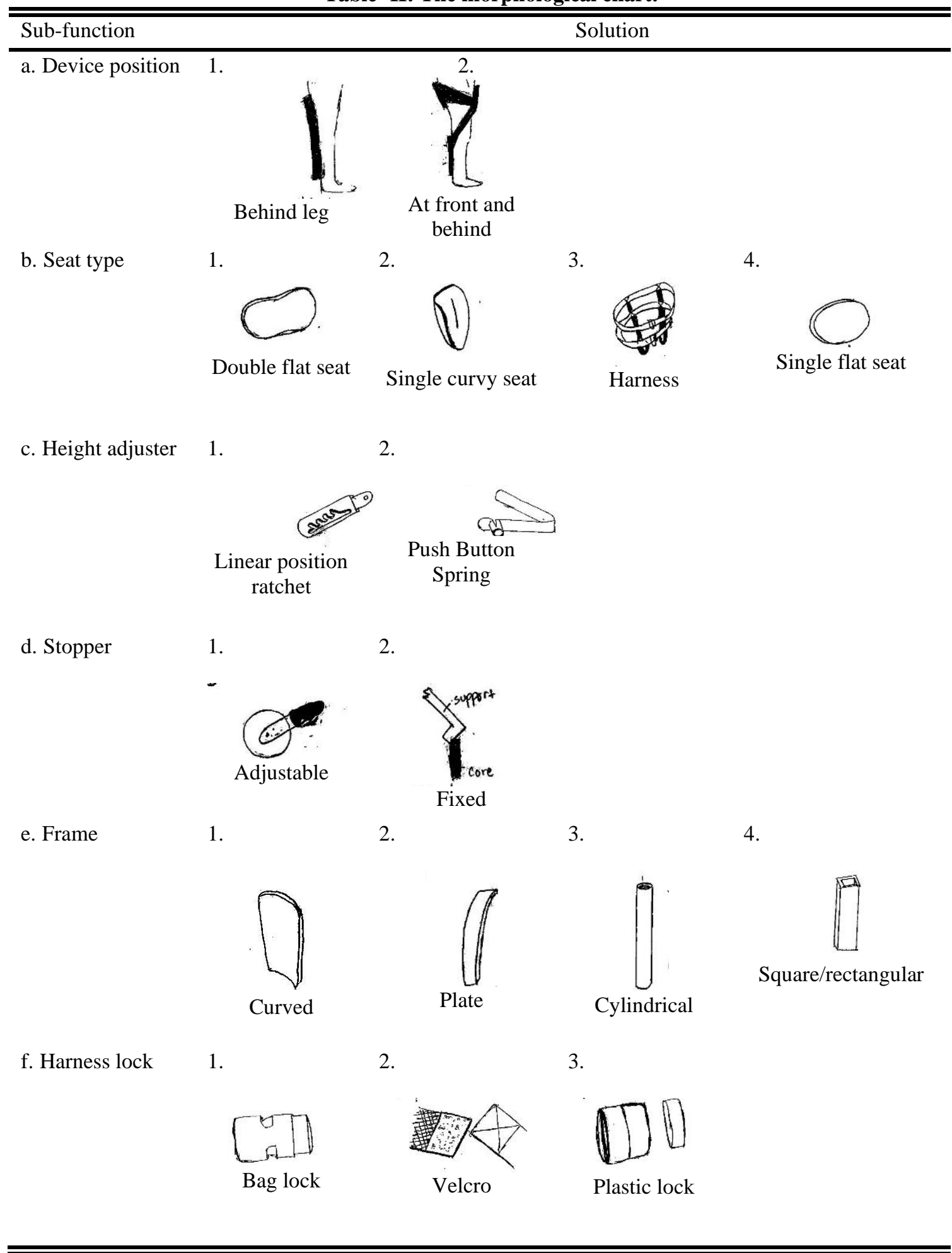

Identifying the DOF (degrees of freedom) is to determine the mobility of the design. The calculation of DOF using the Gruebler's Equation involves $n$, which is the number of links, $J_{p}$, the primary joints and $J_{h}$, the higher-order joints. The written relation is as in Equation (1). This discussion is found in many literatures like Myszka [6], Uicker, Pennock, and Shigley [7], and Erdman, Sandor and Kota [8].

$$
m=3(n-1)-2 J_{p}-J_{h}
$$

The DOF calculated of wearable-chair design is 1 , with $n$, $J_{p}$ and $J_{h}$ are equal to 6, 6 and 2 respectively. The kinematic diagram with the components for this design are shown in Fig. 4. Nagaraja and Rajesh also used rigid body mechanisms in the scotch-yoke system they built for sawing purpose [9]. However, another work by Solepatil and Deore used compliant mechanisms that are made from a single flexible material designed to achieve high accuracy movements [10], although usually the displacement that could be reached by compliant mechanisms is limited to a smaller range.

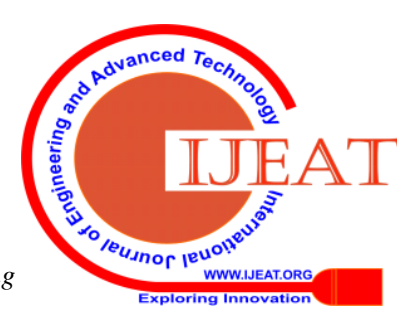




\section{Design and Analysis of a Cam-Actuated Wearable-Chair}

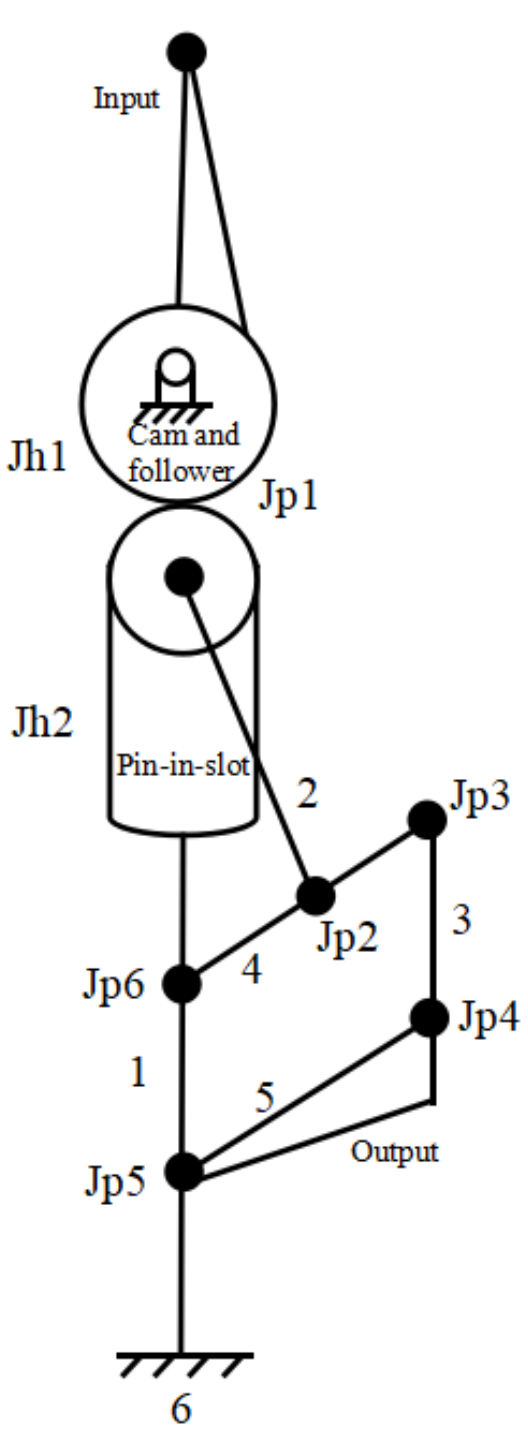

Fig. 4.The wearable-chair kinematic diagram labeled to analyze its mobility.

\section{RESULT AND DISCUSSION}

The simulations and analyses in this paper discusses the motion analysis and stress analysis. It contains the countermeasure to perform the simulations and the findings on both simulations and analyses involving design usability, maximum stress area and FOS (factor of safety).

In order to eliminate the fixable constraints and unnecessary interactions, the fasteners were excluded from the analyses. The cover parts in the design assembly were also excluded for the simulation results in order to have a clearer view of the wearable-chair mechanisms design assembly simulation results. The mechanisms design assembly used and its BOM (bill of materials) is shown in Fig. 5. Materials used are basically iron, steel, and aluminum for most parts as well as pine wood for the covers.

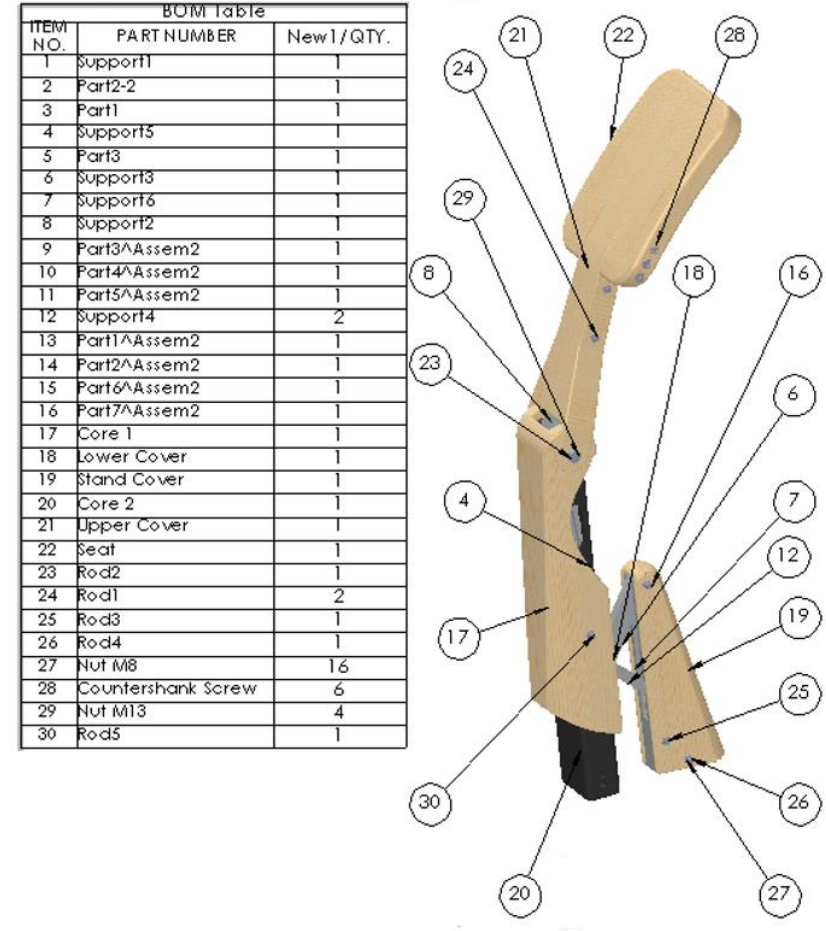

Fig. 5.Mechanisms design assembly of Wearable-chair.

The motion analysis was performed by using SolidWorks software. It was to analyze the usability of this design. This type of analysis is able to predict the motion of the model when load or torque is applied.

In this analysis, a low torque of $100 \mathrm{Nm}$ was applied to the input in which it was supposedly enough to operate the device with gravitational force was in effect. In less than 5 seconds after the simulation was run, the desired motion and position was achieved with no interference during the analysis. The fully-deployed position of the design assembly is shown in Fig. 6.

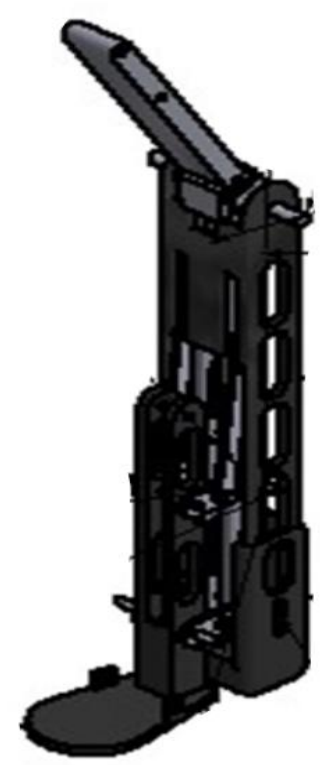

Fig. 6.Final position of the wearable-chair in motion analysis. 
In this paper, stress analysis was performed on the design assembly instead of the part design using Autodesk Inventor. It was to obtain the Von Mises stress distribution for the whole design in order to obtain its FOS. Explanation on FOS can be found in Hibbeler [11] and Nisbett and Budynas [12]. The minimum factor of safety, $n$ required for the design to be considered safe is at least 1 .

$$
n=\frac{s_{y}}{\sigma_{\max }}
$$

Recent work on forces in cams can be found in [13], while general finite element analysis on machines parts is shown by the work in [14]. In this present work, the stress analysis was performed by using Inventor 2017 software. Converting SLDASM file type to STEP file type was necessary for further analysis to be done in Inventor 2017.

This device was designed to sustain a weight less than 100 $\mathrm{kg}$. Thus, one side of this device must be able to sustain $50 \mathrm{~kg}$ of weight. With a force of $490 \mathrm{~N}$ applied to the input in its final position, the Von Mises stress distribution was analyzed as shown in Fig. 7. (a)

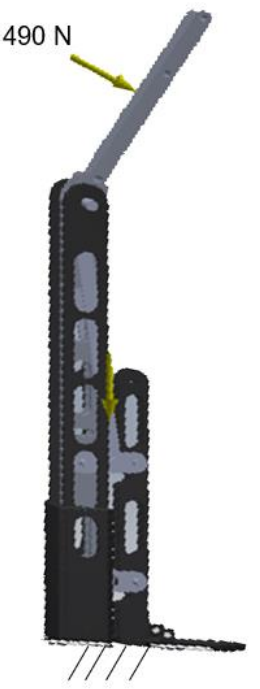

(b)

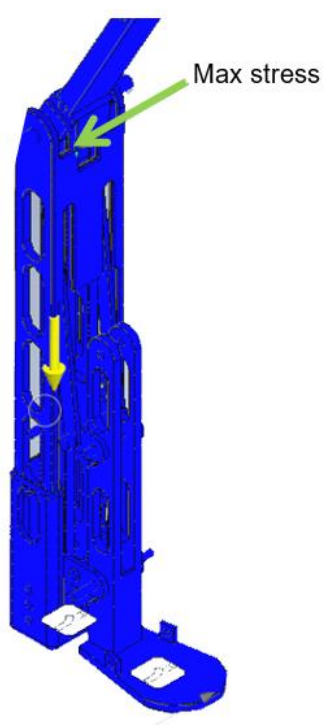

Fig. 7.(a) The boundary condition of the analysis, and (b) the Von Mises maximum stress location.

Fig. 8.

The maximum stress area analyzed in the design occurred in Core1 in Fig. 8 with $317.9 \mathrm{MPa}$. With iron material of 811 MPa yield stress applied to the Core1, the minimum factor of safety of about 1.7 behind the knee [15].

\section{CONCLUSION}

The degrees-of-freedom shows that this design has achieved the desired mobility of 1 . Furthermore, the motion analysis results also agreed to the design mobility and that the mechanisms design should be able to function as desired. Only a small maximum stress area was detected during the stress simulation analysis, and it was considered safe.

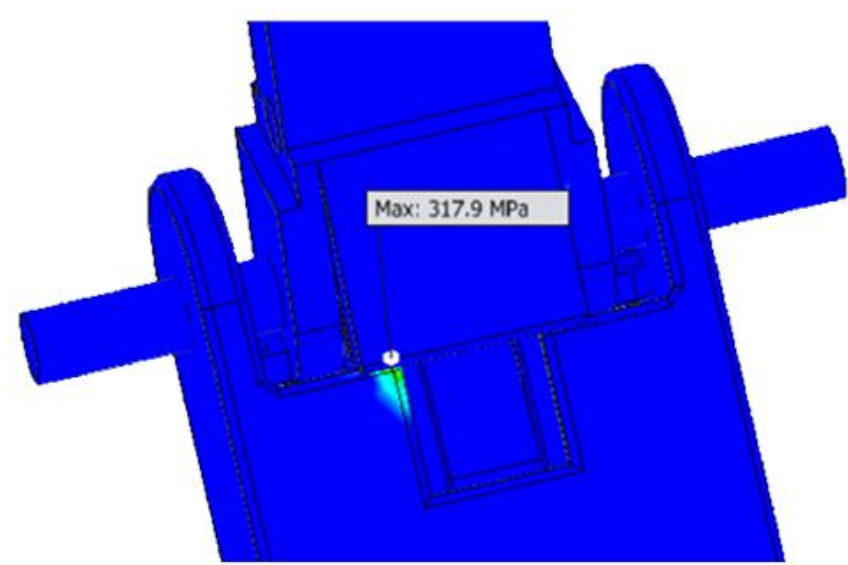

Fig. 9.Maximum stress area in the mechanism design assembly.

\section{ACKNOWLEDGMENT}

The authors would like to thank the support by the Universiti Teknikal Malaysia Melaka (UTeM) that always encourages innovation and the sharing of knowledge. This work has been adapted from the work of Adinda for her Final Year Project report.

\section{REFERENCES}

1. J. Prisco, (2014, August 21). The chair-less Chair, an invisible chair that you can wear. Retrieved October 8, 2018, from http://edition.cnn.com/2014/08/20/tech/innovation/the-chairless-chair/i ndex.html

2. L. Stinson, (2017, June 03). An Exoskeleton That Acts Like a Wearable Chair. Retrieved online: October 8, 2018 from http://www.wired.com/2015/03/exoskeleton-acts-like-wearable-chair/

3. S. O'Riley, (2017, July 17). This Fantastic Device Will Let You Sit Anywhere You Want. Retrieved October 8, 2018, from http://www.ba-bamail.com/content.aspx?emailid=26632

4. G. Pahl, W. Beitz, J. Feldhusen, and K. H.. Grote, Engineering Design: A Systematic Approach $3^{\text {rd }}$ ed. Springer, London, UK, 2007.

5. K. T. Ulrich and S. D. Eppinger, Product Design and Development, $6^{\text {th }}$ ed. McGraw-Hill, New York, 2015.

6. D. H. Myszka, Machines \& Mechanisms: Applied Kinematic Analysis, 4th ed. Pearson, Boston, 2011.

7. J. J. Uicker Jr., G. R. Pennock, and J. E. Shigley, Theory of Machines and Mechanisms, Oxford, New York, 2017.

8. A. G. Erdman, G. N. Sandor, and S. Kota, Mechanism Design : Analysis and Synthesis, Vol. 1, 4th ed. Pearson, Upper Saddle River, 2001.

9. V. Nagaraja and M. Rajesh, "Fabrication of Automated Four-Way Hack Saw Machine by using Scotch Yoke Mechanism," International Journal of Engineering and Advanced Technology (IJEAT), ISSN: 2249 - 8958, 9(1), October 2019.

10. S. Solepatil and N. Deore, "Displacement analysis of compliant mechanism," International Journal of Engineering and Advanced Technology (IJEAT), ISSN: 2249 - 8958, 9(1), October 2019.

11. R. C. Hibbeler and K. B. Yap, Mechanics of Materials, $10^{\text {th }}$ ed, Pearson, New Jersey, 2018.

12. R. G. Budynas and J. K. Nisbett, Shigley's Mechanical Engineering Design, $10^{\text {th }}$ ed. McGraw-Hill, New York, 2015.

13. F. I. Petrescu, R. V. Petrescu, Forces and Efficiency of Cams, IREME Journal, 7(3), p. 507-511, Mar. 2013.

14. F. M. Khan, M. S. Islam, M. Z. Hossain, Design Aspects of an Excavator Arm, IREME Journal, 10(6), p. 437-442, September 2016.

15. A. H. Mohd Zin, Realization od a working prototype of the wearable chair, Final Year Project Report, Universiti Teknikal Malaysia Melaka, Malaysia, 2019. 


\section{AUTHORS PROFILE}

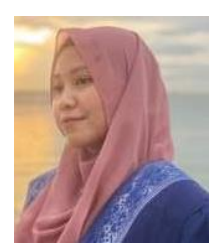

Adinda Hadirah Mohd Zin, is a student at the Universiti Teknikal Malaysia Melaka under the Faculty of Mechanical Engineering. She received her bachelor's degree in Mechanical Engineering from UTeM, graduating in December 2019. This article is based on her work for her undergraduate senior project. Adinda is now pursuing the Master of Engineering degree at UTeM.

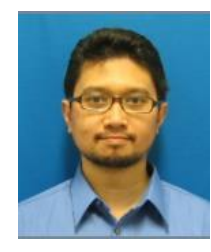

Shamsul Anuar Shamsudin, received the bachelor's degree in Mechanical Engineering from Valparaiso University, master's from Universiti Teknologi Malaysia, and doctorate degree from The University of Dayton. Dr. Shamsudin usually teaches computer-aided design (CAD) using AutoCAD, mechanism design, mechanics of machines, mechanical component design as well as engineering design processes.

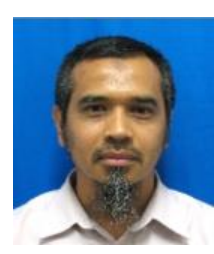

Mohd Nizam Sudin, is a Senior Lecturer with a field of interest that includes engineering and product design process, manufacturing processes, machine design, and optimization. He graduated with a BEng in Mechanical Engineering from Universiti Kebangsaan Malaysia, an M.Sc. from Universiti Putra Malaysia, and a Ph.D. from Denmark Technical University.

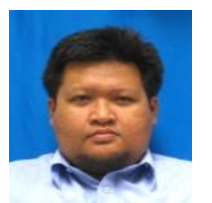

Mohd Nazim Abdul Rahman, is a mechanical engineering lecturer. He received the bachelor's degree from Universiti Teknologi Malaysia, and a master's degree from Universiti Putra Malaysia. Mr. Nazim is an expert in CAD using CATIA, SolidWorks, and AutoCAD. He also worked several years in industry in the field of machine design prior to joining academia.

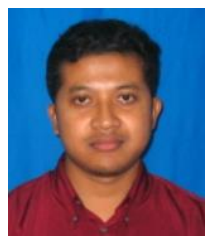

Zairulazha Zainal, is a mechanical engineering lecturer. He received the bachelor's degree from Kyushu Institute of Technology, Japan and a master's degree from Universiti Teknologi Malaysia. Mr. Zairu is an expert in control engineering and instrumentation. $\mathrm{He}$ is currently pursuing a doctoral degree in image processing. 